\title{
Carta de recomendações dos editores de periódicos científicos de educação São Paulo, 2000
}

Levando em consideração a importância da sistematização das publicações na área de humanidades e as peculiaridades da produção científica na área educacional, realizou-se nos dias 22 e 23 de agosto de 2000, na Faculdade de Educação da Universidade de São Paulo, o seminário Política de Publicação Científica em Educação no Brasil Hoje.

O seminário se desenvolveu por meio de exposições organizadas em torno de três mesas-redondas, conforme o temário abaixo transcrito. Contou com a presença de mais de cem participantes, a maior parte dos quais editores de periódicos científicos da área de educação, que, na última sessão, apresentaram as recomendações que constam deste documento, para que sejam encaminhadas às associações de pesquisa, às agências de fomento e instâncias avaliadoras e à comunidade científica em geral.

\section{Temário}

A produção científica na área educacional e o papel dos periódicos especializados

Balanço do papel que vem sendo cumprido pelos periódicos na divulgação e no fomento à qualidade da pesquisa; diferentes linhas editoriais; formas de financiamento e inserção institucional dos periódicos.

\section{Expositores:}

Maria Malta Campos (Editora da Revista Brasileira de Educação); Osmar Fávero (Membro da Diretoria da ANPEd); Águeda Bittencourt (Editora de Pro-Posições). 
Qualidade editorial e sistema classificatório dos periódicos

Análise dos critérios externos de avaliação do conjunto dos periódicos da área; a questão da periodicidade, indexação, exogenia, abrangência e distribuição das revistas.

\section{Expositores:}

Rosaly Fávero Krzyzanowski (FAPESP);

Rosa Maria Bueno Fischer (Editora de Educação \& Realidade).

Arbitragem da produção científica: a editoração

Exame dos problemas práticos do processo de editoração; o papel dos editores, do conselho editorial e dos pareceristas ad hoc; critérios e procedimentos de avaliação dos artigos; aspectos científicos e éticos.

\section{Expositores:}

Luciano Mendes de Faria Filho (Editor de Educação em Revista); Ivany Pino (Editora de Educação \& Sociedade);

Elba Siqueira de Sá Barreto (Editora de Cadernos de Pesquisa).

\section{Recomendações}

1. Que as informações sobre indexação de revistas sejam divulgadas o mais amplamente possível, especialmente entre os editores;

2. Que as questões de ordem ética envolvidas em cada etapa do processo de editoração sejam objeto de uma ampla e contínua discussão;

3. Que os critérios adotados na avaliação e classificação das revistas sejam definidos com maior clareza, especialmente por parte da CAPES, levando em conta as peculiaridades da área de educação e as especificidades de cada região, de cada instituição e dos próprios periódicos;

4. Que em tais avaliações as revistas de periodicidade mais larga não sejam desfavorecidas, de modo que por meio de uma política de publicações se estimule a produção e a qualidade da pesquisa na área da educação em todas as regiões do país; 
5. Que seja estabelecido um diálogo entre os editores e a ANPEd para se discutir os critérios de classificação dos periódicos e os critérios definidores de "cientificidade" e "fator de impacto";

6. Que seja examinada uma forma (uma associação?) de os periódicos terem participação no COMPED (Comitê dos Produtores de Informações Educacionais).

Educação e Pesquisa

São Paulo, 2000

Subscrevem esta Carta as seguintes revistas:

- Educação e Pesquisa, revista da Faculdade de Educação da USP;

- Educação \& Sociedade, do Centro de Estudos Educação e Sociedade (CEDES);

- Cadernos CEDES, do Centro de Estudos Educação e Sociedade (CEDES);

- Estudos Leopoldenses, série Educação, da Unisinos;

- Cadernos de Pesquisa, da Fundação Carlos Chagas;

- Teoria e Prática da Educação, do Departamento de Teoria e Prática da Educação da Universidade Estadual de Maringá;

- Revista de Educação - PUC-Campinas, da Pontifícia Universidade Católica de Campinas;

- Educação \& Realidade, do Departamento de Educação da Universidade Federal do Rio Grande do Sul;

- Educação em Revista, da FaE da Universidade Federal de Minas Gerais;

- Pro-Posições, da Faculdade de Educação da Unicamp;

- Contexto \& Educação, da Unijuí;

- Paradoxa - Projetivas Múltiplas em Educação, da Universo, São Gonçalo, Rio de Janeiro;

- Cadernos de Pesquisa, da Universo, São Gonçalo, Rio de Janeiro; 
- Revista de Educação CEAP, do Centro de Estudos e Assessoria Pedagógica, Salvador, Bahia;

- Ciência \& Educação, do Programa de Pós-Graduação em Educação para a Ciência, da Unesp-Bauru;

- Educar em Revista, da Universidade Federal do Paraná;

- Revista da FAEEBA, da UNEB;

- Ensaio - Pesquisa em Educação em Ciências, do Centro de Ensino de Ciências e Matemática, FaE, UFMG;

- Educação, revista da FE/Programa de PG-PUCRS;

- Revista Brasileira de Estudos Pedagógicos - INEP;

- Temas em Educação, revista do Programa de Pós-Graduação em Educação, Centro de Educação da UFPB;

- Educação em Questão, revista da Universidade Federal de Rio Grande do Norte;

- Revista Educação \& Linguagem, da Faculdade de Educação e Letras, Programa de Pós-Graduação em Educação da Universidade Metodista de São Paulo (Umesp). 